\title{
Analyzing the heterogeneity of farmers' preferences for improvements in dairy cow traits using farmer typologies
}

\author{
D. Martin-Collado, ${ }^{* 1}$ T. J. Byrne, ${ }^{*}$ P. R. Amer, ${ }^{*}$ B. F. S. Santos, ${ }^{*}$ M. Axford, $\dagger$ and J. E. Pryce \\ *AbacusBio Limited, Dunedin 9016, New Zealand \\ †Australian Dairy Herd Improvement Scheme, Melbourne, VIC 3000, Australia \\ ‡Department of Environment and Primary Industries and La Trobe University, Agribio, 5 Ring Road, Bundoora, VIC 3083, Australia
}

\begin{abstract}
Giving consideration to farmers' preferences for improvements in animal traits when designing genetic selection tools such as selection indexes might increase the uptake of these tools. The increase in use of genetic selection tools will, in turn, assist in the realization of genetic gain in breeding programs. However, the determination of farmers' preferences is not trivial because of its large heterogeneity. The aim of this study was to quantify Australian dairy farmers' preferences for cow trait improvements to inform and ultimately direct the choice of traits and selection indexes in the 2014 review of the National Breeding Objective. A specific aim was to analyze the heterogeneity of preferences for cow trait improvements by determining whether there are farmer types that can be identified with specific patterns of preferences. We analyzed whether farmer types differed in farming system, socioeconomic profile, and attitudes toward breeding and genetic evaluation tools. An online survey was developed to explore farmers' preferences for improvement in 13 cow traits. The pairwise comparisons method was used to derive a ranking of the traits for each respondent. A total of 551 farmers fully completed the survey. A principal component analysis followed by a Ward hierarchical cluster analysis was used to group farmers according to their preferences. Three types of farmers were determined: (1) production-focused farmers, who gave the highest preference of all for improvements in protein yield, lactation persistency, feed efficiency, cow live weight, and milking speed; (2) functionality-focused farmers with the highest preferences of all for improvements in mastitis, lameness, and calving difficulty; and (3) typefocused farmers with the highest preferences of all for mammary system and type. Farmer types differed in their age, their attitudes toward genetic selection, and
\end{abstract}

Received December 4, 2014.

Accepted February 25, 2015.

${ }^{1}$ Corresponding author: dmartincollado@abacusbio.co.nz in the selection criteria they use. Surprisingly, farmer types did not differ for herd size, calving, feeding system, or breed. These results support the idea that preferences for cow trait improvements are intrinsic to farmers and not to production systems or breeds. As a result of this study, and some bioeconomic modeling (not included in this study), the Australian dairy industry has implemented a main index and 2 alternative indexes targeting the different farmer types described here.

Key words: trait preference, dairy selection index, breeding objective, farmer type

\section{INTRODUCTION}

Low uptake of genetic selection tools among livestock farmers is one of the reasons for the lack of realization of potential genetic gain in breeding programs (Duguma et al., 2011; Nielsen et al., 2013). It has been argued that if the uptake of genetic selection tools is to be maximized, breeding objectives have to take into account farmers' preferences for improvements in animal traits (Sy et al., 1997; Nielsen and Amer, 2007). However, the determination of farmers' trait preferences is not trivial. Farmers' preferences are known to be heterogeneous (Sy et al., 1997; Ouma et al., 2007), and not accounting for this heterogeneity might bias the estimate of these preferences (Nielsen and Amer, 2007 ) in the sense that the mean preferences might not reflect the preferences of a large proportion of farmers.

Farmers' trait preferences have been analyzed, mainly in developing countries, to inform the design of breeding programs by understanding what kind of animals farmers would like to have. This represents an alternative to the calculation of trait economic weights, which is sometimes difficult because of the poor quality of available data (Nielsen and Amer, 2007), and it is also a way of including the value of nonmarket traits in the economic valuation of livestock (Ouma et al., 2007; Bett et al., 2011). In developing countries, and to a lesser extent developed countries, farmer characteristics are thought to have a strong influence on farmers' 
preferences for improvements in traits, and therefore, variables describing farmer characteristics are usually included in studies analyzing heterogeneity of farmers' preferences (Makokha et al., 2007).

Broadly, 3 methodological approaches have been used to analyze stated farmers' preferences: choice experiments (Bett et al., 2011; Duguma et al., 2011), pairwise comparisons (Byrne et al., 2012), and simpler methods such as ranking traits (Dana et al., 2010; Gizaw et al., 2010). Choice experiments have been widely used to analyze farmers' preferences for animal traits. However, the design of choice experiments is complex, and it is not clear whether or not they reveal the "true" preferences, because of bias derived from the complexity of the choice task (Arentze et al., 2003; Caussade et al., 2005; Nielsen and Amer, 2007). Pairwise comparisons require less intellectual effort from participants than choice experiments, because all items are not compared at once. This pairwise comparison makes choice decisions simpler and therefore may be nearer to "true" preferences (Hansen and Ombler, 2009).

Two general approaches have been used to account for heterogeneity in the analysis of farmers' preferences. Often preferences are analyzed within prior groups of farmers that are then compared. Usually, studies look at different farming systems (Tano et al., 2003; Byrne et al., 2012; Ahlman et al., 2014), different production objectives or segment of the industry (Roessler et al., 2008; Gizaw et al., 2010), or different breeds (Duguma et al., 2011). Alternatively, some studies include factors believed to influence preferences as independent variables in the models used to analyze preferences (Makokha et al., 2007; Ouma et al., 2007) or as interaction terms in the models (Tano et al., 2003). In both approaches, researchers have to make assumptions about the factors affecting preference heterogeneity or about the group of farmers that might have different trait preferences. Predefining groups might be appropriate when the primary interest is describing differentiated farmer types or farms (Byrne et al., 2012; Ahlman et al., 2014); however, when the interest is analyzing preference heterogeneity, prior assumptions might bias the results of the analysis.

Several statistical multivariate methods are designed to analyze variability, which can be applied to farmers' preferences without making prior assumptions about the sources of such variability. Cluster analysis (CA) might be useful in understanding patterns of preferences that are not evident when analyzing the sampled population as a whole. When the variability of preferences is high and the preferences for different alternatives or traits are related to each other, as is usually the case, the combined use of principal component analysis
(PCA) and CA can produce robust results (Ben-Hur and Guyon, 2003; Barnes and Toma, 2012).

The aim of this study was to analyze Australian farmers' preferences for improvements in traits in dairy cows to inform the 2014 review of the national breeding objective (NBO) for the Australian dairy industry, implemented by the Australian Dairy Herd Improvement Scheme. The Australian NBO aims to increase net farm profit. This NBO is translated into a practical breeding tool in the form of a breeding index or set of breeding indexes. The main purposes of the review were to ensure that the indexes remained relevant for improving on-farm profit and were based on strong scientific principles that are consistent with farmers' preferences. In this context, we aimed to analyze Australian dairy farmers' preferences for improvements in traits, which were expected to be highly variable, evaluated in females without making any assumptions on the sources of its variability.

Specifically, the objectives of this paper were (1) to analyze the heterogeneity of dairy farmers' preferences for improvements in cow traits and determine whether there are farmer types with different preferences, and if so, (2) to analyze whether these farmer types differ in their farming systems, in their attitudes toward breeding and genetic evaluation tools, and in their socioeconomic profile.

\section{MATERIALS AND METHODS}

\section{Industry Consultation Survey}

An online survey was developed to explore dairy farmers' preferences for improvements in 13 cow traits: protein yield, cow live weight, fertility, longevity, mastitis resistance, milking speed, temperament, calving difficulty, feed efficiency, lactation persistency, lameness, mammary system, and overall type. The survey gathered information about farmer and farm profiles, farmer attitudes toward breeding tools, and the criteria they use for selecting bulls. All these factors were included as potential aspects influencing farmers' preferences for improvements in traits. Thus, the survey was divided into 2 distinct questionnaires explained below: a questionnaire about farmer' preferences for improvements in traits and a questionnaire about farmer and farm profiles.

The survey was pretested with a group of Australian dairy farmers and industry personnel and then refined before releasing it to farmers of all 6,314 Australian dairy farms. The survey was promoted through traditional and social media. All farmers with e-mail addresses were contacted directly, and underusers of 
Question \# 31

Which of these 2 (hypothetical) herds do you prefer?
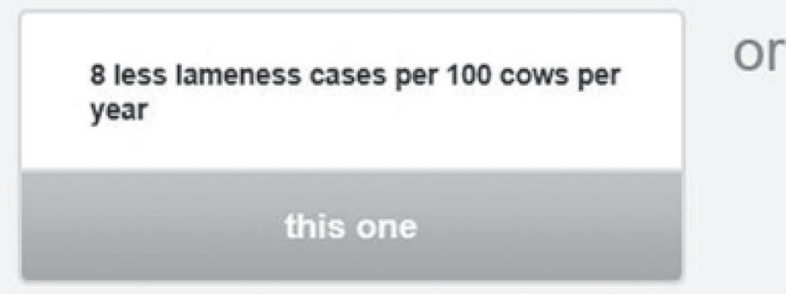

$1.5 \mathrm{~kg}$ more protein per cow per year

" undo last decision

they are equal

this one

$95 \%$ complete

Larger font for questions (easier to read)

Figure 1. Example of question of the 1000Minds (1000Minds Ltd., Dunedin, New Zealand) survey on dairy farmer preferences for cow trait improvements.

Internet technology were supported with the opportunity to be surveyed by phone. Tablet computers were provided at farm walks and field days to facilitate participation. In addition to the farmers that voluntarily completed the survey, 200 farmers were contacted by phone through an external market research organization. The 200 farmers were randomly selected from the list of all Dairy Australia levy-paying farmers (levies are a legal requirement in Australia). The survey produced 618 responses, of which 551 were fully completed by farmers, and these 551 were used for this study.

Part I. Farmers' Preferences for Trait Improvements Questionnaire. We applied a pairwise comparison method using the 1000Minds software (1000Minds Ltd., Dunedin, New Zealand) to assess farmers' preferences for trait improvements because of its simplicity of design and implementation and the lower intellectual effort required compared with other more complex methods (Hansen and Ombler, 2009). The software is based on the PAPRIKA method that further reduces the intellectual effort required with an algorithm that dynamically adapts the questions asked based on the answer to the previous questions, thus eliminating all possible questions that have already been implicitly answered. The software asks a series of questions to respondents, who are asked to choose, repeatedly, between pairs of alternatives until all possible pairs of alternatives are evaluated. A ranking of the presented alternatives is derived from these choices. A detailed description of the algorithm can be found in Hansen and Ombler (2009). The final aim of the study was to inform a breeding objective, and therefore, the interest was in farmers' preferences for improvements rather than for traits per se (Byrne et al., 2012). To do this, the farmer was presented with a choice between 2 alternatives that represented improvements in cow traits of importance in dairy farming systems. Figure 1 presents a sample of a survey choice question.

We evaluated farmers' preferences for improvements in 13 cow traits (Table 1). We considered most of the traits included in the Australian Profit Ranking (APR), which is the selection index used to assess Australian dairy sires, when selecting breeding bulls, at the time of surveying, as well as some other traits that were considered of potential importance for the Australian dairy industry. The current APR consists of 9 traits, which include 4 milk production traits (milk, fat, and protein yield and cow live weight) and 5 nonproduction 
traits (longevity, fertility, mastitis resistance, temperament, and milking speed). Out of these 9 traits milk and fat yield were not included in the survey because protein yield was considered to be the best indicator of farmers' preference for cow milk production. In Australia, payment for milk production is based on milk fat and protein, with a penalty on milk volume, where the most valuable component is protein yield, which is more than twice as valuable as fat yield (e.g., Murray Goulburn Cooperative Co. Limited, 2014). In addition to the 7 APR traits included, we also evaluated the following 6 traits: calving difficulty, feed conversion efficiency, lactation persistency, lameness, mammary system, and overall type. The magnitude of the suggested improvement in each trait was such that our estimate of the economic effect on farm would be as similar as possible across traits. Therefore, if farmers rank one trait more highly than another, their preference is more likely to be driven by perception than by economics. Table 1 presents the magnitude of trait improvements that farmers compared when completing the survey, the economic value per unit of improvement, the economic effect of those improvements for a 100-cow herd, and the assumptions and calculations used to derive these figures. We attempted to present to farmers realistic magnitudes of trait improvements and, therefore, rounded to the nearest integer where possible, avoiding very small or very large numbers. The economic effect of trait improvements was calculated for an average farm. Although the economic effect on farm might not be exact, the levels of trait improvements were estimated to be within the range of industry reality. Therefore, the strategy was to ask farmers to choose between improvements in traits that each have a similar economic effect on an average farm and therefore quantify both the noneconomic motives of farmers' preferences and also the differential economic effect of the traits in their specific farm, compared with the average.

Part II. Farmer and Farm Profile Questionnaire. In this part of the survey, farmers were asked about a set of farmer and farm descriptors that were thought to have a potential influence on farmers' preferences for improvements in traits. Table 2 describes the farmer and farm profile factors analyzed.

This part of the survey was also used to analyze farmer attitudes toward genetic evaluation tools and the importance of certain criteria when buying bulls. Farmer attitudes toward genetic evaluation tools were assessed by asking farmers to rate, in a 5-level Likert scale (Likert, 1932), their level of agreement with specific statements. These statements queried the use of EBV and the level of trust of different components of selection indexes. This kind of approach is widely used in the analysis of people's attitudes in psychometric studies (Mellor and Moore, 2014). We specifically asked farmers about their trust in EBV and in the APR. On the other hand, the importance that farmers gave to different criteria when buying bulls was assessed by asking farmers to rate a predefined set of criteria on a 0 (not important at all) to 5 (extremely important) scale. The list of attitudinal statements and bull selection criteria evaluated are presented in Table 3.

\section{Statistical Analysis}

Analysis of Farmers' Preferences for Trait Improvements. The first step was to describe, by basic statistical descriptors, the ranks of farmers' preferences for trait improvements calculated by the 1000Minds algorithm at the sampled population level. Differences in ranks of preferences across the 13 traits were analyzed using the Kruskal-Wallis test to produce a general overview of farmers' preferences for trait improvements and the degree of variability in these preferences.

A PCA followed by a CA of the principal components (PC) was subsequently used to investigate the patterns of relationships between farmers' preferences for the different trait improvements and to determine whether farmers could be grouped accordingly. We determined the $\mathrm{PC}$ of the trait preferences and implemented a Ward's hierarchical CA of the first 5 PC. Ward's method is one of the most used clustering techniques and commonly outperforms other clustering methods in recovering the true clustering structures (e.g., Ferreira and Hitchcock, 2009). The selection of the number of clusters was based on the loss of inertia (within cluster sum of squares) at each partitioning of clusters (Ward, 1963). The final number of clusters was determined by the partition with the highest loss of inertia. The soundness of the determined number of clusters was verified by analyzing the interpretability of the results (Emtage et al., 2006; Dossa et al., 2011)

Analysis of Differences Between Farmer Types. We described the farmer types according to their preferences for animal trait improvements. We also analyzed the relationship between farmer types and farmer attitudes, criteria used for selecting bulls, and other farm and farmer descriptors. Differences for the normally distributed variables were analyzed with the ANOVA test followed by Duncan's multiple comparisons test to analyze pairwise differences. The nonnormally distributed variables were analyzed with the Kruskal-Wallis test, and multiple comparisons were tested with the Wilcoxon's procedure. Finally, the Fisher's exact test was used to analyze pairwise differences between discrete variables among farmer types. 
Table 1. Cow traits evaluated, magnitude of improvements, and economic effect of those improvements for a 100-cow herd

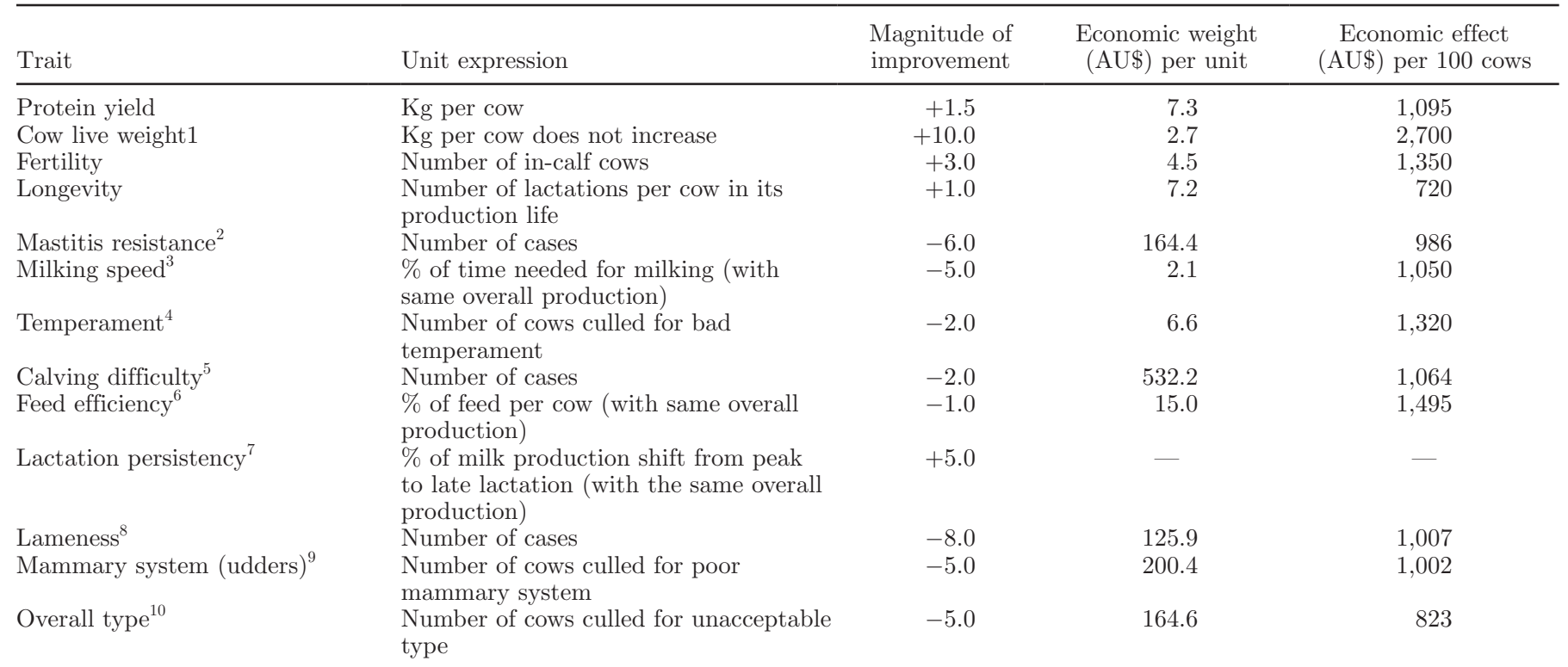

${ }^{1}$ Cow live weight does not increase by $10 \mathrm{~kg}$, assuming an average cow with $550 \mathrm{~kg}$ of live weight, based on the economic weight per kilogram of live weight in the Australian Profit Ranking $(-2.69)$ represented as a saving in costs by holding cow live weight at no change. We asked farmers to consider an alternative that represented cows not getting bigger; this is the favorable direction for the trait (no change). Making cows genetically smaller is not realistic, and making cows genetically bigger comes at a cost. So, it is not economically favorable.

${ }^{2}$ Based on the cost of a mastitis case of $\mathrm{AU} \$ 106.20$, which takes into account milk losses due to discarded milk, treatment antibiotic and labor costs, and incidence of mastitis cases.

${ }^{3}$ Based on a $1 \%$ improvement in milking speed increasing protein yield by $0.58 \mathrm{~kg}$, adjusted based on the assumption that $50 \%$ of the economic weight is not already included in the survival economic value (Pryce et al., 2010).

${ }^{4}$ Based on a $1 \%$ improvement in temperament increasing protein yield by $0.9 \mathrm{~kg}$ (Pryce et al., 2010).

${ }^{5}$ Based on the estimate that the average cost (direct cost of veterinarian call out, risk of cow, and calf death; cost of cow and calf death; costs of loss of milk production) of a very difficult calving (veterinarian or caesarean) is AU $\$ 532$.

${ }^{6}$ Based on a calculation of average daily DMI of $16 \mathrm{~kg}$ (Prendiville et al., 2009; Coleman et al., 2010; de Haas et al., 2012), a total annual DMI of $5,840 \mathrm{~kg}$ of DM, and average feed costs of AU $\$ 0.26 / \mathrm{kg}$ of DM (Dairy Australia, 2013, 2014).

${ }^{7}$ No economic effect was calculated for lactation persistency because in Australia the difference in milk price between season and winter is irrelevant. Nevertheless, farmers might be interested in this shift because greater lactation persistency may lead to less energy imbalance and, thus, less reproductive and health problems (Haile-Mariam et al., 2003). A shift of $5 \%$ of milk production from peak to late lactation was considered to characterize a meaningful improvement for commercial dairy farmers.

${ }^{8}$ Based on the estimate that the average cost (direct treatment costs and cost in lost milk) of a lameness event is AU $\$ 126$.

${ }^{9}$ Based on a genetic correlation of 0.28 with survival, the economic weight for mammary system calculated here represents $0.28 \times$ economic effect for survival.

${ }^{10}$ Based on a genetic correlation of 0.23 with survival, the economic weight for overall type calculated here represents $0.23 \times$ economic effect for survival.

\section{RESULTS}

\section{Traits Preferences at Farmer Population Level}

In the overall ranking of preferences for trait improvements at population level we could distinguish the most preferred and the least preferred trait improvements, as well as a large number of trait improvements with medium preference (Figure 2). Mastitis (mean rank \pm SE: $4.3 \pm 0.14)$ was the most preferred trait followed by longevity $(5.1 \pm 0.14)$ and fertility $(5.4 \pm 0.14)$, whereas the least preferred traits were milking speed $(8.2 \pm 0.14)$, lactation persistency $(8.3 \pm 0.15)$, and cow live weight $(10.4 \pm 0.13)$.

\section{PCA of Farmers' Preferences for Trait Improvements}

The scores of farmers' preferences for cow trait improvements in the first $2 \mathrm{PC}$ are described in Figure 3. These first $2 \mathrm{PC}$ accounted for $26.6 \%$ of the total variability of the farmers' trait improvement preferences, and $5 \mathrm{PC}$ were needed to explain $55.5 \%$ of the initial variability.

\section{CA of the PC}

The CA of the first $5 \mathrm{PC}$ determined the existence of 3 clusters of very similar sizes. We named these 3 farmer clusters ("farmer types" in the rest of the docu- 
Table 2. Farm and farmer profile factors assessed to inform the review of the national breeding objectives for dairy cattle

\begin{tabular}{ll}
\hline Factor of interest & Comments \\
\hline Farmer age & Owner, manager, or other \\
Respondent role in the farm & Among 9 different dairy regions in Australia \\
Farm location & Number of cows calved and milked at peak in the last season \\
Herd size & Liters of milk or kilograms of milk solids in the last season \\
Total farm milk production & Among a range of breeds \\
Cow breed distribution & $\%$ of the herd \\
Cows registered in breed society & $\%$ of the herd \\
Replacements sired by AI or herd bulls & Number of full-time and part-time family and hired work \\
Labor or work force profile & Seasonal, split, or year-round calving \\
Calving system & This factor is in terms of the use or not of grain, grain mix or concentrates, period with no \\
Feeding system & graze, semipermanent or permanent feed pad, and partial or total mixed ration via mixer \\
& wagon. In addition, 5 feeding systems defined by DairyAustralia ${ }^{1}$ were analyzed. \\
\hline
\end{tabular}

${ }^{1}$ The following 5 feeding-system categories have been developed by DairyAustralia based on combinations of the use of grain and pasture and the form in which those are offered to the herd. The systems are categorized according to an increasing scale on intensity of supplementary feeding and are described as low bail, mod-high bail (moderate to high bail), PMR (partial mixed ration), hybrid, and TMR. See the study by Morton et al. (2013) for a complete description of Australian dairy feeding systems.

Table 3. Differences between farmer types regarding their socio-demographic variables and attitudes toward genetic evaluation tools and relative importance given to different criteria when selecting bulls

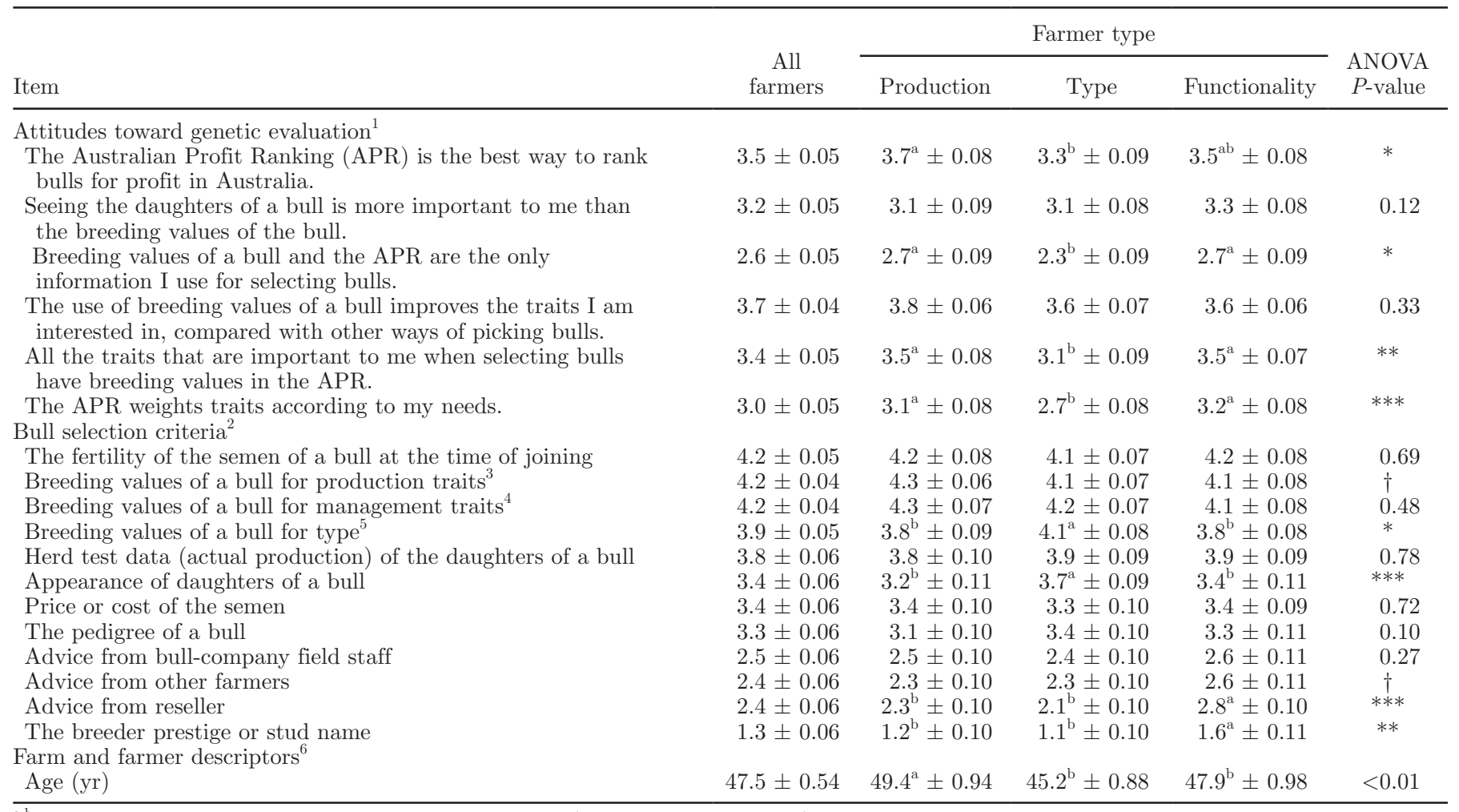

$\overline{\mathrm{a}, \mathrm{b}}$ Means within a row with different superscripts differ (at least with $P<0.05$ ) according to Duncan's multiple comparisons test. The analysis does not include the all sample group.

${ }^{1}$ Mean agreement $\pm \mathrm{SE}$, measured with a Likert scale ranging from 1 (strongly disagree) to 5 (strongly agree).

${ }^{2}$ Mean importance $\pm \mathrm{SE}$, from 0 (not important at all) to 5 (extremely important).

${ }^{3}$ Protein, fat, and milk yields.

${ }^{4}$ Fertility, milking speed, and survival or longevity.

${ }^{5}$ Type trait breeding values are currently provided by the Australian Dairy Herd Improvement Scheme.

${ }^{6}$ Mean \pm SE. Only included variables found to be statistically different between farmer types.

$\dagger P<0.10,{ }^{*} P<0.05,{ }^{* *} P<0.01,{ }^{* * *} P<0.001$. 


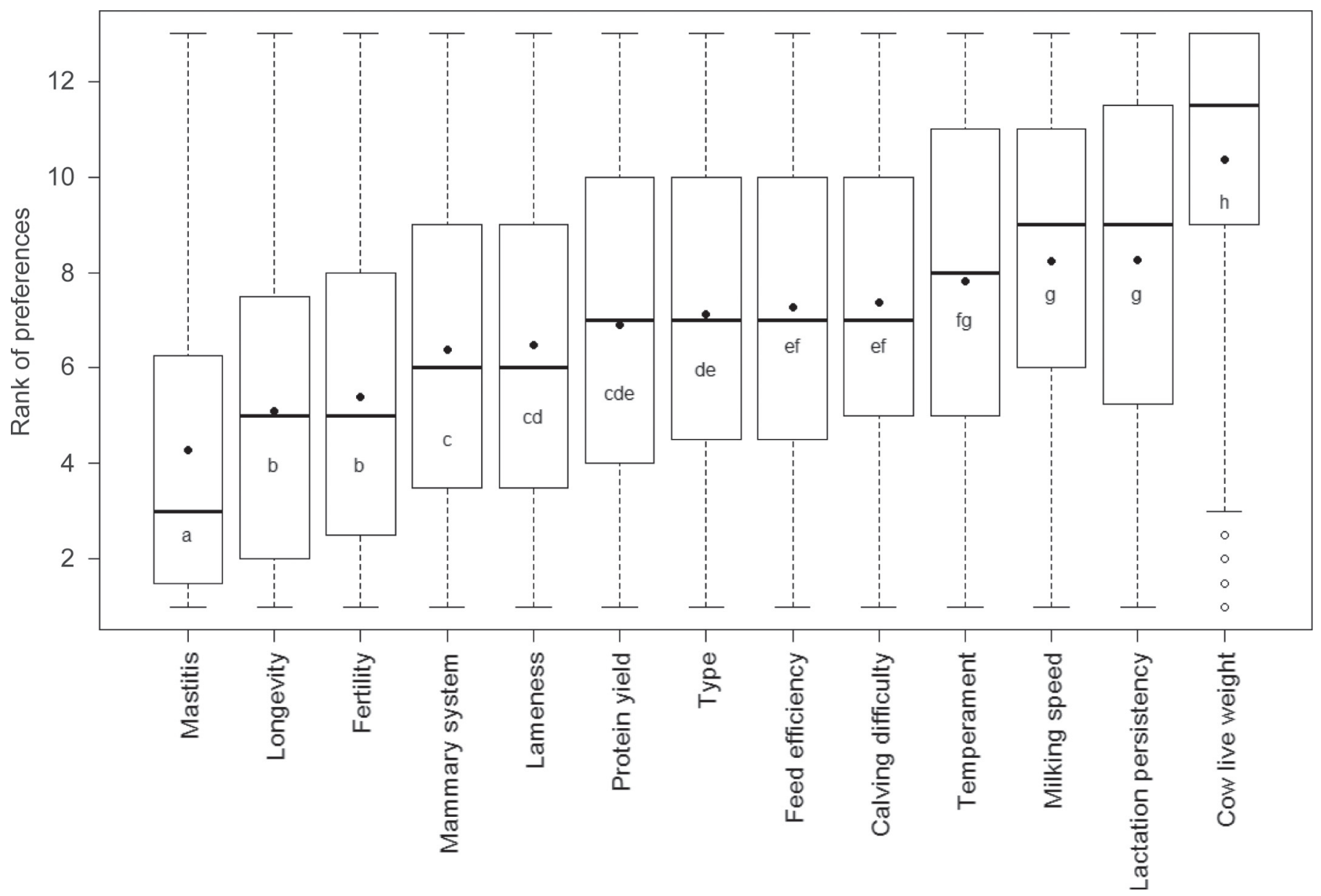

Figure 2. Ranking of Australian farmers' preferences for improvements on dairy cow traits at the whole-farmer-population level. Boxplots represent the mean (black point), median (solid lines), first and third quartiles (contained in the boxes), dispersion (dashed line), and outliers (open points) of the distribution of the ranks of each trait improvement. ${ }^{\mathrm{a}-\mathrm{h}}$ Different letters indicate differences between trait improvement ranks $(P<0.05)$ according to Kruskal-Wallis test of variance. Rank of farmer preferences for trait improvements, as defined in Table 1 , is from 1 (most important) to 13 (least important).

ment) according to the trait improvements to which the farmers had the highest preference. This way, Australian dairy farmers can be classified into productionfocused $(\mathrm{n}=192)$, functionality-focused $(\mathrm{n}=172)$, and type-focused $(\mathrm{n}=187)$ farmers. The preferences for trait improvements of each farmer type are presented in Figure 4.

Production-Focused Farmers. These farmers gave the highest preference to improving longevity (mean rank \pm SE: $4.4 \pm 0.23$ ), feed efficiency (5.2 \pm $0.22)$, and protein yield $(5.3 \pm 0.26)$. Among all farmer types, production-focused farmers gave the highest importance of all to protein yield, lactation persistency $(6.3 \pm 0.25)$, feed efficiency, cow live weight $(9.0 \pm$ $0.25)$, longevity - together with type-focused farmers - and milking speed $(6.9 \pm 0.26)$. Conversely, they gave the lowest importance of all the farmer types to improving mastitis $(5.8 \pm 0.27)$, lameness $(8.1 \pm 0.23)$, and mammary system $(8.4 \pm 0.21)$.

Functionality-Focused Farmers. These farmers gave the highest preference to mastitis (mean rank \pm SE: $2.8 \pm 0.17)$, followed by lameness $(4.6 \pm 0.26)$, calving difficulty $(5.2 \pm 0.22)$, and fertility $(5.4 \pm 0.25)$. Among all farmer types, functionality-focused farmers gave the highest preference to mastitis, lameness, calving difficulty, fertility, and temperament $(7.3 \pm 0.27)$, the latter 2 together with type-focused farmers.

Type-Focused Farmers. These farmers preferred improvements in mammary system (mean rank $\pm \mathrm{SE}$ : $3.7 \pm 0.15)$, longevity $(4.0 \pm 0.19)$, and mastitis $(4.1 \pm$ $0.20)$ the most. Among all farmer types, type-focused farmers gave the highest preference to mammary system, type $(4.9 \pm 0.19)$, longevity $(4.0 \pm 0.19)$ - together with production-focused farmers, fertility $(4.8 \pm 0.21)$, 


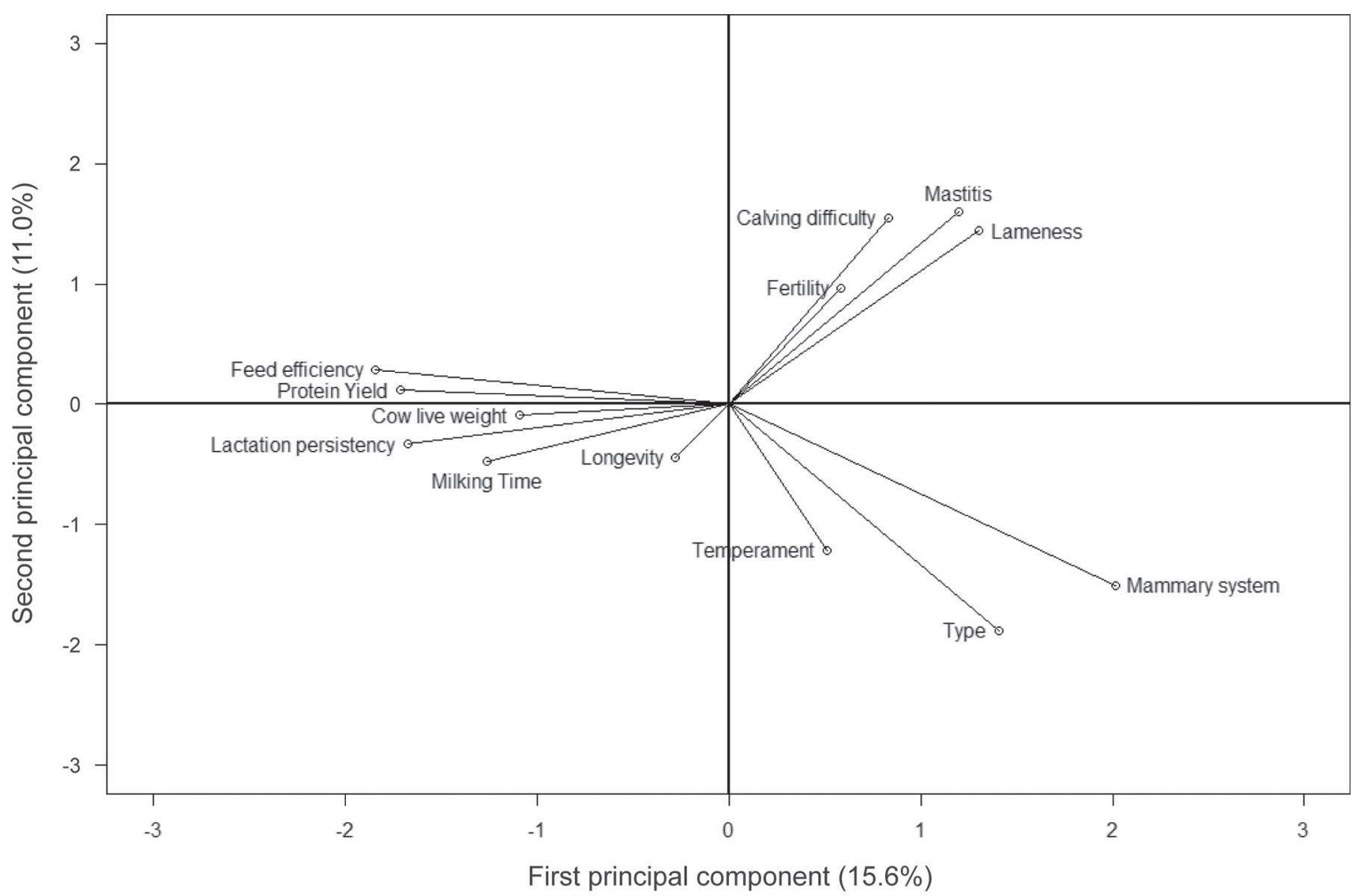

Figure 3. Scores of the preferences for improvements on cow traits on the first 2 principal components. Percentages shown are the initial variation explained by each of the principal components.

and temperament $(7.9 \pm 0.25)$ - the latter 2 together with functionality-focused farmers. On the contrary, type-focused farmers considered protein yield $(8.5 \pm$ 0.22 ) the trait of lowest importance in comparison with the 2 other farmer types.

\section{Description of Farmer Types}

We found that the 3 farmer types identified in this study differed in their attitudes toward genetic selection tools, in the criteria they used to select bulls, as well as in some farm and farmer descriptors (Table 3)

Attitude Toward Genetic Selection Tools. Overall, the utility of APR and EBV was viewed quite positively across all farmer types, although some farmers consider that some important traits do not have EBV and that the APR does not weight traits according to their needs. However, farmers usually used more sources of information to select bulls than solely EBV and APR (Table 3). Although this global overview is applicable to all farmer types, types differed in the intensity of their attitudes toward genetic selection tools. Type-focused farmers were less confident in genetic prediction (APR and EBV) than production-focused and functionallyfocused farmers. Similarly, type-focused farmers agreed less than the other types with the statements regarding the importance of the APR, the adequacy of the traits included in the index, and the relative weighting of the traits. Note that in all the farmer types the mean agreement with attitudinal statements was intermediate, meaning that although differences were found between farmer types, none of the types presented very positive or very negative attitudes toward genetic tools.

Bull Selection Criteria. Across all farmer types the most important criteria for the selection of bulls was the fertility of the semen and the EBV of the bull for production and management traits. These were followed by EBV for type and herd test data of the daughters of the bull. The least important criteria were related to external advice (from bull-company field staff, other farmers, or the reseller), which highlights the high importance of farmers' personal criteria and their lack of 
Production-focused farmers $(n=192)$

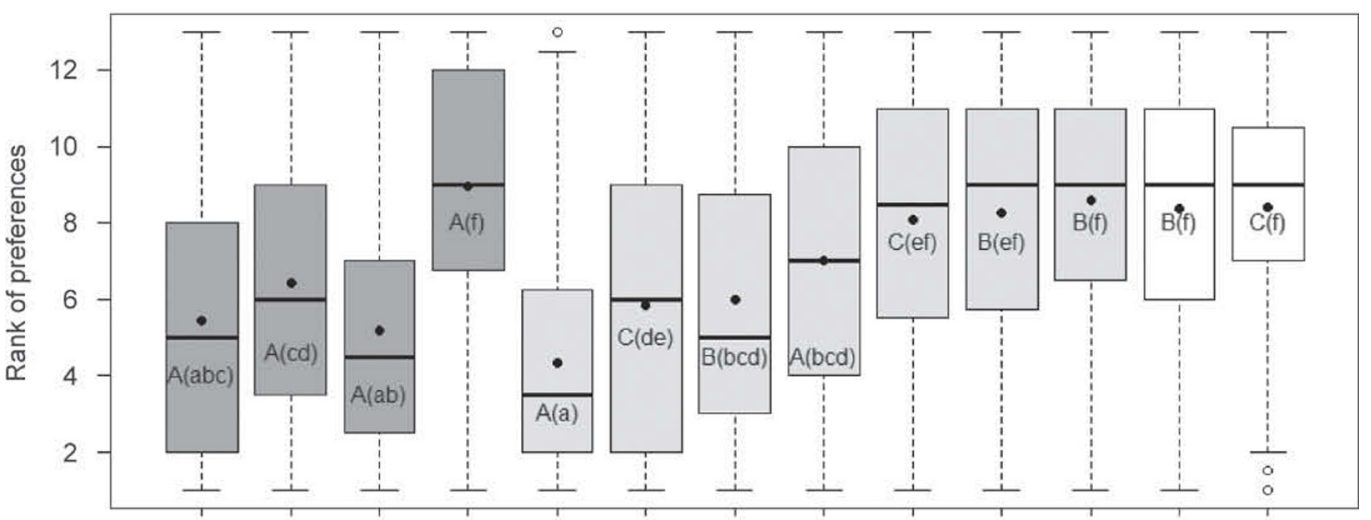

Functionality-focused farmers $(n=172)$

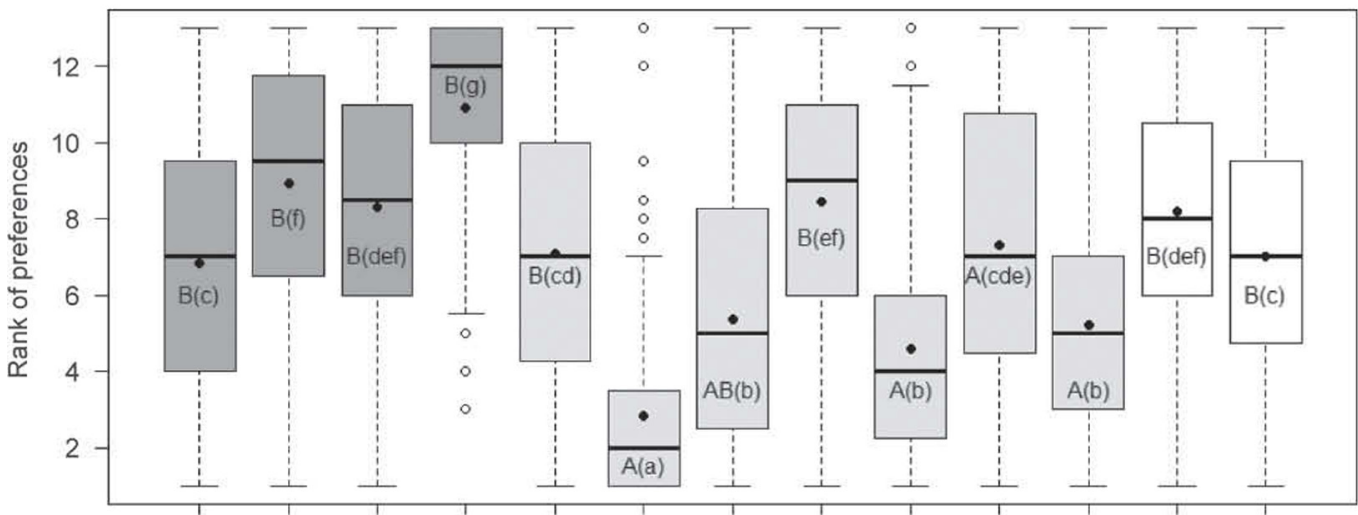

Type-focused farmers $(n=187)$

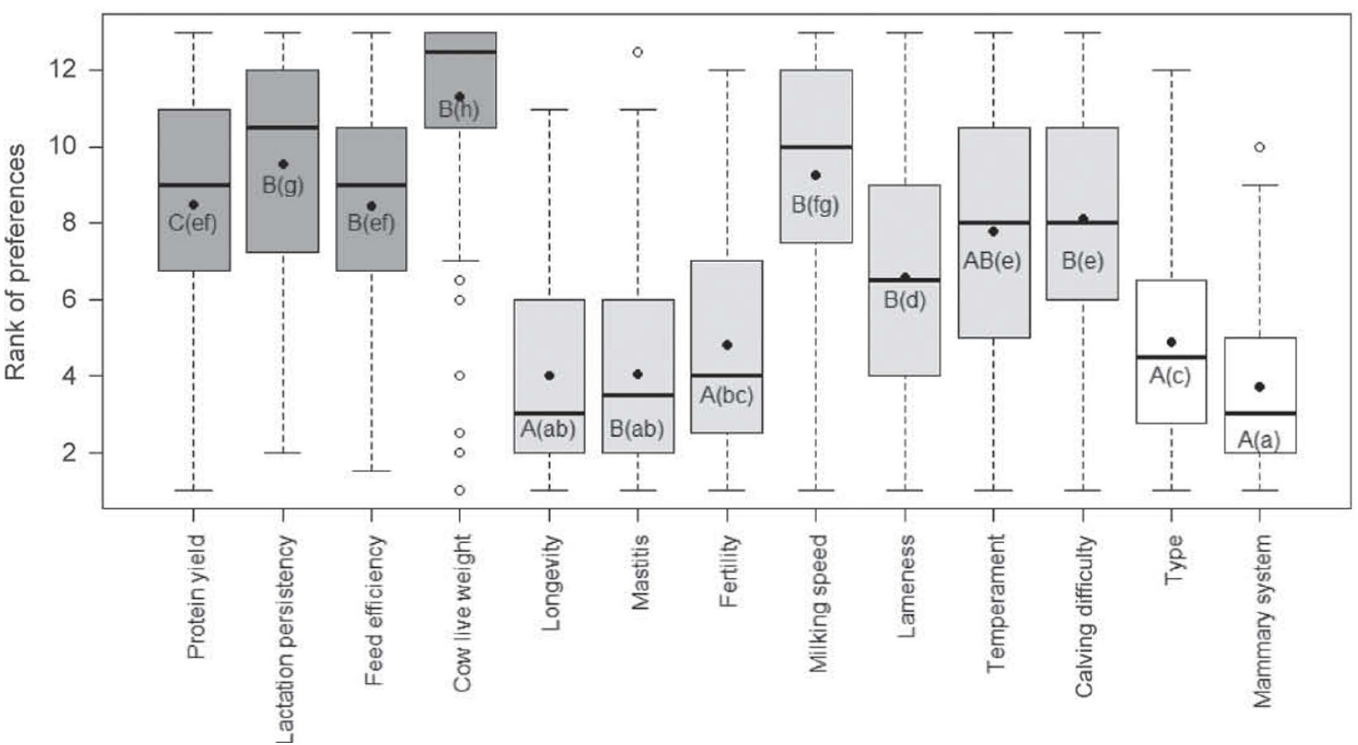

Figure 4. Description of farmer types regarding their preferences for cow trait improvements. Boxplots represent the mean (black point), median (solid lines), first and third quartiles (contained in the boxes), dispersion (dashed line), and outliers (open points) of the distribution of the ranks of each trait. Dark gray boxes refer to production traits, light gray boxes refer to functional traits, and white boxes refer to type traits. ${ }^{\mathrm{A}-\mathrm{C}}$ Rank means of trait preferences with different uppercase letters differ among farmer types (at least with $P<0.05$ ) according to KruskalWallis test of variance. ${ }^{\mathrm{a} h}$ Rank means within a box with different lowercase letters differ between trait preferences within farmer types (at least with $P<0.05)$ according to the Kruskal-Wallis test of variance. 
trust in external advice. Although this global overview of the importance of bull selection criteria applied to all farmer types, types differed in the importance they gave each of them (Table 3). Type-focused farmers gave higher importance to type EBV (mean of 4.1 on a $0-5$ scale with 5 indicating greatest importance to the farmer) and to the appearance of the daughters of the bull (3.7) than production-focused (3.8 and 3.2, respectively, for type EBV and daughter appearance) and functional-focused farmers (3.8 and 3.4, respectively, for type EBV and daughter appearance). Conversely, production-focused farmers tended (ANOVA $P$-value $=0.06)$ to give more importance to production $\mathrm{EBV}$ (4.3) than the other farmers (4.1). Finally, functionalfocused farmers gave more importance, although it was low, to breeders' prestige (1.6) and to advice of reseller (2.8) than the production-focused farmers (1.2 and 2.3, respectively, for breeders' prestige and the advice of reseller) and type-focused farmers (1.1 and 2.1).

Farm and Farmer Descriptors. We found only a few differences in farmer and farm profiles across farmer types. Age seemed to be related to farmers' preferences for cow trait improvements (Table 3). Production-focused farmers were the oldest of the 3 types. Farmer types also had different percentages of the herd registered with a breed society $\left(\chi^{2} P\right.$-value $\left.<0.001\right)$; $41 \%$ of the type-focused farmers had a least two-thirds of the herd registered in a breed society compared with 24 and $22 \%$ of production-focused and functionalfocused farmers, respectively. Note that we did not find any differences between farmer types regarding calving systems or any of the variables describing feeding or feeding systems. We also did not find statistical differences between farmer types regarding the breeds they have. However, in a posterior CA directly on the traits preferences (results not shown), we detected that Holstein farmers were more prone to be classified as type focused, whereas Jersey farmers were more prone to be classified as production focused.

\section{DISCUSSION}

\section{Determination of Farmer Types to Account for Patterns of Preference for Cow Trait Improvements}

The most preferred trait improvements for Australian dairy farmers at the whole-farmer-population level, for the magnitude of improvement provided, were a reduction of mastitis followed by an increase of longevity and fertility. However, Australian dairy farmers can be divided into 3 types according to the pattern of their preferences for cow trait improvements, and none of the types match with the average pattern of preferences at population level (Figures 2 and 4); production- focused farmers gave the highest preference to improvements in longevity, protein yield, and feed efficiency; functionality-focused farmers preferred improvements in mastitis the most; and type-focused farmers gave the highest preference to improvements in mammary system, longevity, and mastitis. Therefore, in situations where farmers' preferences for trait improvements are likely to be heterogeneous (as was the case here for the dairy industry in Australia), mean values of farmers' preferences may give an incomplete and biased view of the farmers' preferences. Moreover, mean preferences do not account for the existence of different groups of farmers with specific needs. This is particularly important for the development and revision of breeding objectives of national effect, because the consideration and correct identification of farmer types (regarding trait improvement preferences) allows tailored selection indexes to be defined, with higher chances of increased adoption (Sy et al., 1997; Nielsen and Amer, 2007).

We have analyzed farmers' trait preferences, studying the preference heterogeneity per se without making any assumption on the source of such heterogeneity; it is usually approached in the literature by looking at the preferences of predefined groups of farmers (e.g., Sy et al., 1997; Duguma et al., 2011; Byrne et al., 2012). Using a multivariate approach to analyze preference heterogeneity enables the determination of patterns of trait preferences that account for the relationship between trait preferences and that are not biased by the selected sources of preference variability. We have seen that differences in patterns of trait preferences in the Australian dairy industry are intrinsic to farmers and not to the production system or the breed. However, production system, breed, or farmer features might be influencing the preferences for specific traits, as it has been seen in other studies for other species and countries (see subsection Farm and Farmer Profiles below), but these effects vanished when analyzing all preferences as a whole. Therefore, consideration needs to be given, in the design of breeding programs, breeding objectives, and selection indexes, to the existence of farmer types with different patterns of preferences for trait improvements.

\section{Differences Between Farmer Types}

Farmer Attitudes and Bull Selection Criteria. Farmer types showed different attitudes toward genetic selection, aligned with the variable importance given to the different criteria used for buying bulls. Typefocused farmers seemed to place less trust than the rest of the types in the APR as the best way to rank and select bulls and showed the least support for the traits included in the index and their weightings (Table 
3). However, the analysis did not reveal differences between production-focused and functional-focused farmers in this regard. Logically, type-focused farmers gave the highest importance of all the farmer types to the appearance of the daughters of the bull and to bull breeding values for type when buying semen. This way, type-focused farmers tended to use selection criteria that have lower efficacy for overall profitability than using solely production and management trait EBV. It could be argued that including type trait EBV reduces the population overall profitability; however, it might help to engage type-focused farmers into using selection indexes. It is important to achieve a balance between suboptimal overall profitability (achieved through incorporation of type traits in the index) and increasing adoption, which in turn might increase genetic gain and therefore overall profitability.

Additionally, we have shown how type-focused farmers actually gave high importance to functional EBV (e.g., longevity, mastitis, and fertility) and not just to type EBV (Figure 4). Interestingly, dairy type traits have been found to be genetically correlated with milkproduction traits (Visscher and Goddard, 1995; HaileMariam et al., 2014). Hence, although more research is needed to clarify this point, there seems to be a gap between what type-focused farmers might be looking for when selecting for type traits and what they are actually selecting for.

Farm and Farmer Profiles. Factors such as farm size and calving or feeding system were expected to explain some of the variability in farmers' preferences for trait improvements, but we did not find significant differences between farmer types for any of the farm descriptors. However, in a univariate analysis of the survey results, we observed that the importance given to specific traits was related to some of the farm features (our unpublished data). Seasonal-calving farmers gave higher preference (ANOVA $P$-value $<0.05$ ), mean rank $( \pm \mathrm{SD}) 4.9 \pm 0.26$, to an improvement in cow fertility compared with farmers of split-calving herds (5.5 $\pm 0.20)$ and all-year-round herds $(5.8 \pm 0.28)$ and to maintaining cow live weight (ANOVA $P$-value $<0.001$ ), mean rank $9.6 \pm 0.25$, compared with split-calving herds $(10.7 \pm 0.19)$ and all-year-round herds (10.7 \pm $0.23)$. There was also no clear relationship between farmers' preferences and breed when analyzing the PC clusters.

Farmer types do not seem to be strongly linked to farm descriptors, production systems, or breeds, which indicates that other factors not considered might influence farmers' preference patterns. Some of these could be related to socioeconomic or cultural aspects of the farming style (Soini et al., 2012). However, we found age to be the only social factor differentiating farmer types. Production-focused farmers tended to be older than functionality- and type-focused farmers, which might be related to the fact that in the past dairy cattle were mostly selected for production traits and to the reluctance of aged farmers to modify their farming style. Other sociocultural factors, such as education and income, have been found to influence farmer attitudes, preferences, and decision making (Makokha et al., 2007; Martin-Collado et al., 2014). These factors were not included in this study because they were, initially, thought to be of reduced importance within the Australian dairy industry context. However, in the light of the results of this study, the importance of considering wider farmer sociocultural features when analyzing trait preferences and the drivers of trait preference variability is now recognized.

\section{Study Methodology}

Statistical Methods. We have shown how different multivariate statistical methods, e.g., PCA and CA, can be applied to analyze, in depth, farmers' preferences. In this study, PCA proved to be a very useful technique for preprocessing data before the CA, as has been the case in many other studies in many different fields (e.g., Ben-Hur and Guyon, 2003; Nainggolan et al., 2011; Ficko and Boncina, 2013). The CA of PC allowed us to determine an optimum number of clusters using the Ward criterion, which could not be determined when using CA directly on the farmers' trait preferences (our unpublished data). Principal component analysis also provides a useful framework for visualizing the data. The plot that presents farmers' trait-preference variables according to their score in the first $2 \mathrm{PC}$ gives a clear representation of the relationships between the preferences for different traits, which accounts for the maximum variability in the initial data set (Figure 3).

It could be argued that the use of ranks instead of relative weights causes an artificial increase in the variability of the data, because farmers are forced to rank trait improvements even when their preferences for both of them are very close. We were aware of this issue, and therefore, the survey allowed respondents to give equal preference to any pair of traits (Figure 1). We believe that the high variance found in farmers' preferences for trait improvements might truly reflect the real variability of farmers' preferences.

It should also be noted that we attempted to equalize the modeled profit effect of the trait improvements presented to farmers. The profit effect calculations are likely to be imprecise, given the complexities of a 
farm production system, and the fact that the profit calculations were conducted in advance of a more substantial review of trait weightings for the Australian NBO. These factors may have created some bias. Also, the economic effect calculated for most of the traits was approximately $\mathrm{AU} \$ 1,000$, but the calculated effect of longevity was AU $\$ 715$ and of cow live weight, AU $\$ 2,753$. Therefore, it could be expected that farmers would give higher preference to cow live weight and lower to longevity compared with the rest of the traits. However, this was not observed (Figures 2 and 4). This result may suggest that farmers might not consider live weight to be as important as the economic calculations suggest, and the reverse for longevity.

Finally, perfect sample representation cannot be ensured because of the sample selection process being only partly random. However, given the quite large sample size (551 farmers) and the random selection of 200 farmers (see Methods), any potential bias should be small. Furthermore, if a bias exists it is more likely to happen in the group size of the farmer types (and not the in the description of the types themselves - see next section), and therefore no extrapolation to the industry has been made regarding the relative importance of each of the farmer types.

Cluster Soundness. The first $2 \mathrm{PC}$ accounted for $26.6 \%$ of the variability in the initial variables (Figure 3), and 5 PC were needed to explain $55.5 \%$ of the variability. This reflects the large variability in the initial preference data for all traits. To test whether the number of PC considered in the CA influenced the optimum number of clusters, we ran CA for 2 to $10 \mathrm{PC}$ and always found the optimum solution (according to the Ward criterion) to be 3 clusters, which although the number of farmers in each cluster varied slightly, represented the same production-functionality-type division. It should be noted that the high variability of trait preferences leads to the existence of clusters with undefined borders in the sense that there were farmers with intermediate preferences between farmer types, forming a continuum of farmers' preferences rather than 3 totally discrete farmer types. This can also be observed in the minor movement of farmers between clusters when a different number of PC is considered. To further test the soundness of the clustering we compared the results of the Ward's hierarchical CA with those using other clustering methods such as K-means and neural gas clustering. The latter 2 methods also determined the existence of the same 3 clusters (production-functionality-type division), although again the number of farmers in each cluster varied slightly. We also analyzed the differences in farm and farmer profiles between farmer types derived from the different clustering methods, and no remarkable differences were found compared with the Ward hierarchical clusters. Hence, we can conclude that the farmer types determined are robust because they are consistently found by different clustering methods and were not affected by considering a larger number of PC. Furthermore, we have seen that the 3 farmer types showed differences in other factors not used in the clustering, such as attitudes and selection criteria, which help in the interpretability of the results and reinforces the robustness of the clustering (Emtage et al., 2006; Dossa et al., 2011).

Farmers' preferences may change with time, and therefore, the farmer type effects identified in this study may have a time dependency. Farmer preferences may change in the mid-term if production conditions change. However, this mid-long-term time dependency is intrinsic to genetic improvement. In the short term, farmers may give more importance to those traits that are more critical at the time of the survey (e.g., fertility at mating or calving ease at calving time). However, it is reasonable to expect that most of the farmers have a mid-long-term view of their business and therefore answered the survey accordingly. The outcomes of the study (Figures 2 and 4) do not indicate otherwise.

\section{Study Application in the Review of Australian Dairy NBO}

This study was implemented to inform the 2014 review of the Australian dairy NBO and the development of potential selection indexes. As a result of this study, and some bioeconomic modeling, a primary index and 2 alternative indexes were released. These 3 indexes include new traits and offer a range of options to choose from when selecting bulls. The primary index is in line with the average preferences (Figure 2). The 2 alternative indexes reflect the preferences identified for functionally-focused and type-focused farmer types (Figure 4). In reality, the economic weights for the majority of traits were calculated based on economic principles; however, several trait weightings were calculated using a desired-gains approach. The inclusion of new traits was defined by considering the results of the survey.

The fact that farmers could be grouped differently is important when a significant proportion of the industry was represented in the survey. The formulation of economic selection indexes that align with the preferences of specific groups of farmers might lead to increased adoption of these selection indexes by industry.

\section{CONCLUSIONS}

Australian dairy farmers' preferences for trait improvements are heterogeneous. However, 3 general farmer types with different patterns of preferences for 
trait improvements were found. These types can be broadly described as production-focused farmers, with a stronger preference for production trait improvements, such as longevity, feed efficiency, and protein yield; functionality-focused farmers, with a stronger preference for functional trait improvements such as mastitis, lameness, calving difficulty, and fertility; and type-focused farmers, with the strongest preference for improvements in type traits, including mammary system and overall type but also with a high preference for longevity and fertility. These 3 farmer types are not totally discrete, and there are several farmers with intermediate preferences between pure types. We did not find a clear relationship between farmer types and farming systems or breeds, which supports the idea that preferences for trait improvements are intrinsic to farmers and not to farming systems or breeds. This reinforces the approach of analyzing farmer trait improvement preference heterogeneity per se, without making assumptions about the sources of variability of preferences.

\section{REFERENCES}

Ahlman, T., M. Ljung, L. Rydhmer, H. Röcklinsberg, E. Strandberg, and A. Wallenbeck. 2014. Differences in preferences for breeding traits between organic and conventional dairy producers in Sweden. Livest. Sci. 162:5-14. http://dx.doi.org/10.1016/j. livsci.2013.12.014.

Arentze, T., A. Borgers, H. Timmermans, and R. DelMistro. 2003. Transport stated choice responses: Effects of task complexity, presentation format and literacy. Transp. Res. Part E Log. Transp. Rev. 39:229-244. http://dx.doi.org/10.1016/S13665545(02)00047-9.

Barnes, A. P., and L. Toma. 2012. A typology of dairy farmer perceptions towards climate change. Clim. Change 112:507-522. http:// dx.doi.org/10.1007/s10584-011-0226-2.

Ben-Hur, A., and I. Guyon. 2003. Detecting stable clusters using principal component analysis. Pages 159-183 in Functional Genomics: Methods and Protocols. M. J. Brownstein and A. Kohodursky, ed. Humana Press, New York, NY.

Bett, H. K., R. C. Bett, K. J. Peters, A. K. Kahi, and W. Bokelmann. 2011. Estimating farmers' preferences in selection of indigenous chicken genetic resources using non-market attributes. Anim. Genet. Resour. 49:51-63. http://dx.doi.org/10.1017/ S2078633611000348.

Byrne, T. J., P. R. Amer, P. F. Fennessy, P. Hansen, and B. W. Wickham. 2012. A preference-based approach to deriving breeding objectives: applied to sheep breeding. Animal 6:778-788. http:// dx.doi.org/10.1017/S1751731111002060.

Caussade, S., J. D. D. Ortúzar, L. I. Rizzi, and D. Hensher. 2005. Assessing the influence of design dimensions on stated choice experiment estimates. Transp. Res. Part B Method. 39:621-640. http://dx.doi.org/10.1016/j.trb.2004.07.006.

Coleman, J., K. M. Pierce, D. P. Berry, A. Brennan, and B. Horan. 2010. Increasing milk solids production across lactation through genetic selection and intensive pasture-based feed system. J. Dairy Sci. 93:4302-4317. http://dx.doi.org/10.3168/jds.2009-2591.

Dairy Australia. 2013. Dairy Farm Monitor Project, Victoria Annual Report 2012/13. Accessed Dec. 3, 2014. http://www. dairyaustralia.com.au/ /media/Documents/People\%20and\%20 business/Business-management/Dairy\%20Farm\%20Monitor\%20 Project/Victoria/2012-13/2012-13\%20Vic\%20Dairy\%20FMP.pdf.
Dairy Australia. 2014. Dairy Farm Monitor Project, New South Wales Annual Report 2012/13. Accessed Dec. 3, 2014. http://www. dairyaustralia.com.au/ /media/Documents/People\%20and\%20 business/Business-management/Dairy\%20Farm\%20Monitor\%20 Project/NSW / 2012-13/DFMP\%20NSW\%20Annual\%20 Report\%202012-13.pdf.

Dana, N., L. H. van der Waaij, T. Dessie, and J. M. van Arendonk. 2010. Production objectives and trait preferences of village poultry producers of Ethiopia: Implications for designing breeding schemes utilizing indigenous chicken genetic resources. Trop. Anim. Health Prod. 42:1519-1529. http://dx.doi.org/10.1007/s11250-010-96026.

de Haas, Y., M. P. L. Calus, R. F. Veerkamp, E. Wall, M. P. Coffey, H. D. Daetwyler, B. J. Hayes, and J. E. Pryce. 2012. Improved accuracy of genomic prediction for dry matter intake of dairy cattle from combined European and Australian data sets. J. Dairy Sci. 95:6103-6112. http://dx.doi.org/10.3168/jds.2011-5280.

Dossa, L. H., A. Abdulkadirb, H. Amadoua, S. Sangarec, and E. Schlechta. 2011. Exploring the diversity of urban and peri-urban agricultural systems in Sudano-Sahelian West Africa: An attempt towards a regional typology. Landsc. Urban Plan. 102:197-206. http://dx.doi.org/10.1016/j.landurbplan.2011.04.005.

Duguma, G., T. Mirkena, A. Haile, A. M. Okeyo, M. Tibbo, B. Rischkowsky, J. Sölkner, and M. Wurzinger. 2011. Identification of smallholder farmers and pastoralists' preferences for sheep breeding traits: Choice model approach. Animal 5:1984-1992. http:// dx.doi.org/10.1017/S1751731111001029.

Emtage, N., J. Hernbohn, and S. Harrison. 2006. Landholder typologies used in the development of natural resource management programs in Australia-A review. Australas. J. Environ. Manage. 13:79-94.

Ferreira, L., and D. B. Hitchcock. 2009. A comparison of hierarchical methods for clustering functional data. Comm. Stat. Simul. Comput. 38:1925-1949. http://dx.doi.org/10.1080/03610910903168603.

Ficko, A., and A. Boncina. 2013. Probabilistic typology of management decision making in private forest properties. For. Policy Econ. 27:34-43. http://dx.doi.org/10.1016/j.forpol.2012.11.001.

Gizaw, S., H. Komenb, and J. A. M. van Arendonk. 2010. Participatory definition of breeding objectives and selection indexes for sheep breeding in traditional systems. Livest. Sci. 128:67-74. http:// dx.doi.org/10.1016/j.livsci.2009.10.016.

Haile-Mariam, M., P. J. Bowman, and M. E. Goddard. 2003. Genetic and environmental relationship among calving interval, survival, persistency of milk yield and somatic cell count in dairy cattle. Livest. Prod. Sci. 80:189-200. http://dx.doi.org/10.1016/ S0301.6226(02)00188-4.

Haile-Mariam, M., O. Gonzalez-Recio, and J. E. Pryce. 2014. Prediction of liveweight of cows from type traits and its relationship with production and fitness traits. J. Dairy Sci. 97:3173-3189. http:// dx.doi.org/10.3168/jds.2013-7516.

Hansen, P., and F. Ombler. 2009. A new method for scoring additive multi-attribute value models using pairwise rankings of alternatives. J. Multi-Criteria Decision Anal. 15:87-107. http://dx.doi. org $/ 10.1002 /$ mcda. 428 .

Likert, R. 1932. A technique for the measurement of attitudes. Arch. Psychol. 22:5-55.

Makokha, S. N., J. T. Karugia, S. J. Staal, and W. Oluoch-kosura. 2007. Valuation of cow attributes by conjoint analysis: A case study of Western Kenya. Afr. J. Agric. Res. Econ. 1:95-113.

Martin-Collado, D., K. Soini, A. Mäki-Tanila, M. A. Toro, and C. Díaz. 2014. Defining farmer typology to analyze the current state and development prospects of livestock breeds: The Avileña-Negra Ibérica beef cattle breed as a case study. Livest. Sci. 169:137-145. http://dx.doi.org/10.1016/j.livsci.2014.09.003.

Mellor, D., and A. Moore. 2014. The use of Likert scales with children. J. Pediatr. Psychol. 39:369-379. http://dx.doi.org/10.1093/ jpepsy/jst079.

Morton, J., P. Brightling, and S. Little. 2013. Feeding the genes. Interactions between feeding system and APR and ABVs in dairy cows. Australian Dairy Herd Improvement Scheme and Dairy Australia. Accessed Dec. 3, 2014. http://www.adhis.com.au/v2/downv2. 
nsf/ (ContentByKey)/e499d47ab5d98f00ca257ba6001feee3/\$file/ adhis $\% 20$ feeding $\% 20$ the $\% 20$ genes $\% 20$ final $\% 20$ full $\% 20$ report.pdf.

Murray Goulburn Cooperative Co. Limited. 2014. Supplier Handbook, Southern Milk Region. Accessed Dec. 3, 2014. http://www.mgc. com.au/media/16707/Southern-Milk-Region-Supplier-Handbook. pdf.

Nainggolan, D., M. Termansen, M. S. Reed, E. D. Cebollero, and K. Hubacek. 2011. Farmer typology, future scenarios and the implications for ecosystem service provision: A case study from southeastern Spain. Reg. Environ. Change 13:601-614. http://dx.doi. org/10.1007/s10113-011-0261-6.

Nielsen, H. M., and P. R. Amer. 2007. An approach to derive economic weights in breeding objectives using partial profile choice experiments. Animal 1:1254-1262. http://dx.doi.org/10.1017/ S1751731107000729.

Nielsen, H. M., P. R. Amer, and T. Byrne. 2013. Approaches to formulating practical breeding objectives for animal production systems. Acta Agric. Scand. Sect. A-Anim. Sci. 64:2-12. http://dx.doi.or $\mathrm{g} / 10.1080 / 09064702.2013 .827237$.

Ouma, E., A. Abdulai, and A. G. Drucker. 2007. Measuring heterogeneous preferences for cattle traits among cattle-keeping households in east Africa. Am. J. Agric. Econ. 89:1005-1019. http://dx.doi. org/10.1111/j.1467-8276.2007.01022.x.

Prendiville, R., K. M. Pierce, and F. Buckley. 2009. An evaluation of production efficiencies among lactating Holstein-Friesian, Jersey, and Jersey $\times$ Holstein-Friesian cows at pasture. J. Dairy Sci. 92:6176-6185. http://dx.doi.org/10.3168/jds.2009-2292.
Pryce, J., J. van der Werf, M. Haile-Mariam, B. Malcolm, and M. Goddard. 2010. A Technical Manual Describing the Australian Profit Ranking (APR) Index. Australian Dairy Herd Improvement Scheme (ADHIS), Melbourne.

Roessler, R., A. G. Drucker, R. Scarpa, A. Markemann, U. Lemke, L. T. Thuy, and A. Valle Zárate. 2008. Using choice experiments to assess smallholder farmers' preferences for pig breeding traits in different production systems in North-West Vietnam. Ecol. Econ. 66:184-192. http://dx.doi.org/10.1016/j.ecolecon.2007.08.023.

Soini, K., C. Diaz, G. Gandini, Y. de Haas, T. Lilja, D. Martin-Collado, F. Pizzi, EURECA - Consortium, and S. J. Hiemstra. 2012. Developing a typology for local cattle breed farmers in Europe. J. Anim. Breed. Genet. 129:436-447. 10.1111/j.1439-0388.2012.01009.x.

Sy, H. A., M. D. Faminow, G. V. Johnson, and G. Crow. 1997. Estimating the value of cattle characteristics using and ordered Probit model. Am. J. Agric. Econ. 79:463-476.

Tano, K., M. Kamuanga, M. D. Faminow, and B. Swallow. 2003. Using conjoint analysis to estimate farmers' preferences for cattle traits in West Africa. Ecol. Econ. 45:393-407. http://dx.doi. org/10.1016/S0921-8009(03)00093-4.

Visscher, P. M., and M. E. Goddard. 1995. Genetic parameters for milk yield, survival, workability, and type traits for Australian dairy cattle. J. Dairy Sci. 78:205-220. http://dx.doi.org/10.3168/ jds.S0022-0302(95)76630-9.

Ward, J. H. 1963. Hierarchical grouping to optimize an objective function. J. Am. Stat. Assoc. 58:236-244. 